\title{
Crura ultrastructural alterations in patients with hiatal hernia: a pilot study
}

\author{
L. Fei · G. del Genio $\cdot$ L. Brusciano $\cdot$ V. Esposito • \\ D. Cuttitta $\cdot$ F. Pizza $\cdot$ G. Rossetti $\cdot$ V. Trapani · \\ G. Filippone $\cdot$ F. Moccia $\cdot$ A. del Genio
}

Published online: 22 June 2007

(C) Springer Science+Business Media, LLC 2007

\section{Erratum to: Surg Endosc \\ DOI 10.1007/s00464-006-9043-5}

The following errors in this article (Vol 21, No. 6, pp. 907911) should be corrected: M. Francesco should be replaced with F. Moccia. The right address for the Department of Public Health, Human Anatomy Unit, (affiliation 3) is via L. Armanni 5, I-80138 Naples, Italy.

Springer regrets these errors.

The online version of the original article can be found under doi:10.1007/s00464-006-9043-5

\footnotetext{
L. Fei $(\bowtie) \cdot$ D. Cuttitta · V. Trapani · G. Filippone ·

F. Moccia

Unit of Surgical Digestive Physiopathology,

Second University of Naples,

via Pansini 5, I-80131 Naples, Italy

e-mail: landino.fei@tin.it

G. del Genio · L. Brusciano · F. Pizza · G. Rossetti ·

A. del Genio

First Division of General and Gastrointestinal Surgery,

Second University of Naples, Second University of Naples,

via Pansini 5, I-80131 Naples, Italy

V. Esposito

Department of Public Health, Human Anatomy Unit,

Second University of Naples,

via L. Armanni 5, I-80138 Naples, Italy
} 